\title{
Metathesis in Arabic: A Comparative Study
}

\author{
Raid Mohammad Saleh Khassawneh ${ }^{1^{*}}$, Islam Mousa Al-Momani ${ }^{2}$, Nibal Abdelkarim Malkawi ${ }^{3}$ \\ ${ }^{1,2}$ Al- Balqa Applied University/ Princess Alia University College \\ ${ }^{3}$ Al-Balqa Applied University-Al-Salt College
}

*Corresponding Author: Raid Mohammad Saleh Khassawneh, Al- Balqa Applied University/ Princess Alia University College, Jordan

\begin{abstract}
The researchers have carried out an analysis of metathesis in Arabic, English and other languages in order to explore whether it is caused by slips of tongue, the absence of mind during the process of speech production, or as a phonological phenomenon that results from pure sound change connected with the realm of morphology. This paper claims in general that metathesis is a phonological phenomenon of all languages including Arabic in both the colloquial and the standard forms. It also aims at giving a comprehensive and descriptive presentation of the distribution of metathesis in Arabic.
\end{abstract}

\section{INTRODUCTION}

Metathesis has generally been treated as a minor sound change. Although they agree on the definition and causes of metathesis with some differences among them, both western and Arab linguists approach it from different perspectives. While western linguists study metathesis as a phonological phenomenon that results from pure sound change, Arab linguists, ancient ones in particular, view and connect it with the realm of morphology. However, in this research we tried to approach it synchronically and diachronically attempting to explore it and investigate why Arabic and English speakers metathesize numerous lexical items during communication. So, the focus of this paper is on metathesis, the process whereby in certain languages, under certain conditions, sounds appear to switch positions with one another.

Generally speaking, the tendency toward change seems to be a universal intrinsic behavior of language. Hadn't language been on a constant process of change, it would have been labeled as a dead language as Baugh (2002)has suggested. The makeup of a language hardly remains static over a long period of time since it changes through usage. Whether phonological, morphological or syntactic, some of the linguistic changes remain vague and cannot be explained with certainty. A language can be approached either synchronically or diachronically. Nevertheless, the explanation of why a certain language behaves in a way or another remains sometimes in the realm of mere guessing. All languages posses a desirability toward achieving a systematic and symmetrical structure. Consequently, language keeps changing systematically rather than haphazardly to reach such a perfect state. Moreover, emphasis is on the importance of the role of communication in language development.

As a universal linguistic phenomenon, metathesis results from the language tendency to modify and simplify its structure and to make the process of speech production smooth and easy. The principle is the same, but its application varies according to the peculiarities of each language. In this sense, each language seems common and peculiar at the same time.

There are general factors of linguistics changes that apply with different degrees among languages. They include assimilation, dissimilation, stress, metanalysis, and metathesis, etc. though metathesis is not as common as other processes affecting sounds in language, such as assimilation or deletion, it does occur as a regular phonological process in synchronic systems in a wide range of languages. The change from $/ \mathrm{nb} /$,for example, to $/ \mathrm{mb} /$ can be described in simple terms as place assimilation of the target $/ \mathrm{n} /$ in the context of a following $/ \mathrm{b} /$, thereby yielding $/ \mathrm{mb} /$; or, in traditional linear formalism, $/ \mathrm{n} /-/ \mathrm{m} /-\mathrm{b} /$.

Metathesis is defined in different ways; it is, generally speaking, the interchange of two sounds in a word or in a linear ordering. Spoonerism is considered a special kind of metathesis caused by slips of 
the tongue or due to the absence of mind during the process of speech production; this latter view is read from a psychological perspective. Special attention is paid to the study of metathesis in some Arabic accents mainly because it occurs more frequently in the colloquial contexts of Arabic; in addition it studies child language basically the type produced as a result of their short memory during their early stage of acquiring language.

Searching thoroughly in ancient books, Arab linguists have found many example words that testify the site replacement or metathesis in Arabic, but rules of metathesis are rarely productive. This is why they are most likely to be discussed from the point of view of historical linguistics; and even there, their sporadic nature gives them a definitely marginal character. Ibn Duraid (Vol.3, P 431) in his book entitled "Al Jamharah" wrote a chapter about this topic in which he assumed that the letters replaced in site and position are proclaimed to be dialects. But recently this proclaim is considered to be odd among recent authentic scholars and researchers because inversion happens between sounds not letters. Thus, the phenomenon is not dialectal but phonological in all languages. After all, it seems that despite the fact that numerous cases of metathesis are reported in language, our basic knowledge lacks the full range of metatheses that are possible in language, under what conditions metathesis applies, why metathesis happens, and how metathesis interacts with other processes affecting sound structure.

\section{LITERATURE REVIEW}

Many linguists tend to define metathesis and classify it into a kind of transposition, inversion or a sound shift on the word level. It is a process in which two sounds replace their positions within the same word. Thus, in a string of sounds where we would expect the linear ordering of two sounds to be ...xy..., we find instead ...yx....This phenomenon is also called "Al Qalb al Makany" in Arabic, i.e. place inversion by Arab linguists. An overall view of this process sees it as a result of pronunciation difficulty when certain sounds in a language are successive to each other. This leads to difficulty in pronouncing them and thus inverting them in order to make it easier for pronunciation and even more harmonious for the ear to hear.

Some linguists and researchers believe that metathesis occurs in language due to misunderstanding and mistakes in hearing; it also occurs in all languages as a type of speech error and is a common feature of child phonology. Karamat Usainhas said,: "the change and inversion of sounds are caused by short memory and most recent sounds are saved there. Inversion becomes so frequent in the sounds the hearer cannot recognize while sounds repeatedly heard on a regular basis are copied in brain and retention finds no difficulty in recognizing them." (Al-Kantouri :15,1915). To this, Bergstrasser says,: " We find in language a certain aspect of sound change when any one given sound forwarded or rewarded from its original position; the explanation for this is that the order sound production is much easier imagined than done so in actual production." (Bergstrasser:36,1982). Vendryeshas stated that:" metathesis or inversion is caused by the same factor for producing similar and alike sounds in that both of them are due to misunderstanding and false perception."( Vendryes:17,1972).

The western approach to metathesis is more appropriate since metathesis is the output of sound change. Many linguists tend to define metathesis and classify it into a kind of transposition, inversion or a sound shift on the word level. They also consider Spoonerism as part of metathesis but with no historical function. They merely associate it with certain jaw-breaking tongue tests. Wardhaugh considers it as a kind of sound change which switches the position of letters. Bloomfield sees it as "the interchange of two phonemes within a word." (Bloomfield:391,1973). Hockett was so close to this perspective when he asserted that it replaces an older form by a newer one with the difference that the two parts have been interchanged. His definition seems more inclusive as it includes metathesis on the level of a single word as in the words disintreggation and disintegration, or on the level of compound words as in standsown for sandstone; besides, it includes the level of the sentence with which he associates with slip tongues. Whitefield generally defines it astransferring an element from one syllable to another. This movement is restricted only to the movement of the unstressed towards the stressed syllable. He cites coccodrillo instead of crocodile- two Italian words. Interestingly, he suggests that the interchange of two or more elements correspond to the order of expiration; the order of the movements of the speech organs from the interior to the exterior; from the throat to the lips, is the catalyst of this type of metathesis. P-k sequence is replaced by k-p as in the word skeptic from the Latin word specere. 
Metathesis is originally a Greek word. It is called Mosquito in French and Moutique in Spanish. In Arabic it is referred to as Al- galb al makani, as mentioned earlier. Al Jundi (1978) associates metathesis with Arabic dialects. Ayyob(1968)has approached it from a Freudian perspective; for him it is an individual psychological process that results from psychological mistakes. This definition is closer to spoonerism which results from slips of tongue with which Bollinger (1975) associates with miscoding misting. From a historical perspective, spoonerism is named after William Spooner(18441930). He was a clergy man whose high speed of articulation led to a number of slips of the tongue, such as "is the dean dizzy?" instead of "is the dean busy?" Spoonerism is sometimes used deliberately in some acts and scenes on stage for comic goals.

\section{OBJECTIVES AND Methodology}

This research paper is concerned with the analysis of metathesis in Arabic from different perspectives and it aims at answering the following questions:

- Is metathesis and its recurrence in Arabic language classified as part of development or a language error?

- When and why could metathesis occur?

- What governs the occurrence of metathesis?

- How could metathesis be interpreted?

In order to bring the objectives of the paper to a consistent end, the researchers follow a complex system of methodology. The historical- descriptive approach has been applied to get hold of a historical background and record a descriptive analysis of metathesis and its development in the domain of linguistics. The comparative approach has, also, been used to analyze metathesis in Arabic and compare it to those in English and other languages. Finally, the researchers follow the analytical approach to analyze metathesis and the data used here are an amalgamation of genuine sentences uttered by native speakers of Arabic. Authentic grammar books are also used as sources; furthermore, a few Arab grammarians and professors of Arabic language are referred to for their consultation and testing the validity of the data. The following symbols are used to represent certain Arabic sounds that do not match IPA symbols:

/ț/ voiceless dental emphatic stop

/ș/ voiceless alveolar emphatic fricative

$/ \mathrm{x} /$ voiceless velar fricative

$/ \dot{\mathrm{g}} /$ voiced velar fricative

$/ \mathrm{h} /$ voiceless pharyngeal fricative

/ç/ voiced pharyngeal fricative

/q/ voiceless uvular stop

\subsection{Hypothesis}

The paper is designed to analyze metathesis in order to weigh up the explanatory and satisfactoriness of this notion. This paper aims at checking whether metathesis caused by slips of tongue or due to the absence of mind during the process of speech production, or as a phonological phenomenon that results from pure sound change connected with the realm of morphology.

\section{DISCUSSION}

\subsection{Causes of Metathesis}

Metathesis has been discussed according to diachronic and synchronic methodologies. Arab and European linguists have thoroughly investigated the causes of metathesis. Pyles, Jesperson and Lord suggest satisfactory reasons for such changes. On the other hand there is more disagreement on the causes of metathesis in Arabic language and many of the tribal accents connected to it. Some who disagree with metathesis attack it on the ground that it is an artificial phenomenon. However, What linguists have in common is the feature that metathesis has the tendency to increase the ease of articulation. Metathesis may result from the brain's working faster than the other vocal organs so that 
the nerve impulse which directs the movement of those organs sometimes get out of synchronization resulting in slips of the tongue.

Lord (1974) suggests that metathesis occurred in the earlier stages of language when it was not completely recognized as a fully established system. In other words when it was considered "newly born" or immature. During this stage, there was confusion concerning the classification of both consonants and vowels. It is associated with collective mistakes in pronunciation where these chronologically later established themselves to be correct of their own like the word uncomfortable which people pronounce as uncomferable!

For Arab linguists, metathesis is more common among Semitic languages than other families. They state five reasons for the appearance of metathesis in Arabic. They emphasize the multiplicity of dialects as the main reason. From a positive perspective, metathesis has been viewed as a means of enriching the vocabulary of language; some lexical items in Arabic like 'alwa? il' became 'alawil' for poetic necessity. The third suggested reason is associated with the mistakes of narration during the early oral stage of the Arabic tribal language. In other situations, the internal mechanism of Arabic led to the modification of the less common phonological sequence to the direction of the more available ones. The cluster ' $d z z$ ' was replaced by ' $d \zeta$ ' since the latter is more common, so ' $d \zeta a z a b a$ ' became 'dzabaza' because they were geographically isolated. Certain words that witnessed metathesis became distinctive features of their accent. In general, metathesis is more common in colloquial Arabic than in the standard one. The standard is restricted to the form known as the classic and which is documented in traditional Arabic dictionaries without being in actual use in the everyday language of communication for a long time.

Metathesis or site inversion refers back to all the above mentioned cases altogether with the difficulty of successive sounds within the same word, and hearing misunderstanding; however, the phonological factor has greater importance here. While variation in the linear ordering of elements is typical in the domain of syntax, it is comparatively striking in phonology. It differs in nature from most other phonological processes which are typically defined in terms of a single sound, or target, which undergoes a change in a specified context. Metathesis is well recognized in historical linguistics, but it can also be seen in performance errors, in such tongue-slips as 'aks' for 'ask', or in the phenomenon of 'Spoonerism'. Synchronically, metathesis is viewed more as a performance factor responsible for Spoonerism and other erratic surface deviations. The reversal of sounds such as $/ s k /$ to $/ \mathrm{ks} /$, defies such a simple formalism given that metathesis seems to involve two targets, with each essentially providing the context for the other. Due in part to the distinct nature of the process, metathesis has traditionally resisted a unified and explanatory account in phonological theory. The apparently distinct nature of metathesis has also resulted in the perpetuation of, what one might refer to as, the "metathesis myth", the commonly held view of metathesis as sporadic and irregular, restricted to performance errors, child language or sound change. This view is regularly expressed in the linguistic literature, including the most up-to-date instructional texts and dictionaries. Vendryes has asserted that "when two parts of the same word tend to replace their position under the impact of accentuation or stress or simply due to their private positioning, it is always the stronger phoneme that deserves distinguishing and thus inversion occurs."(Vendryes:18,1972).

\subsection{Metathesis in Arabic}

\subsubsection{Perspectives of old Arab Linguists}

Arab and Western linguists agree on the definition and the essence of metathesis. Nevertheless, each group approaches it from a different perspective. Western researches stem their concern from phonology whereas Arab linguists relate it to morphological developments. Consequently, almost all the Arabic great lexicons are classified according to the root of the verb. Arab linguists tend to count which clusters of letters are more common in order to decide on which root is the original and which witnessed transposition or inversion.

Arab linguists and scholars who studied this phenomenon hundreds of years ago provided us with varied perspectives about it, disagreement was dominant among them. While Ibn Faris, a Kuffan grammarian, confirmed the existence of metathesis and its recurrence in Arabic language is an essential part of language development and change. Others like Ibn Darstawayh, a Basran grammarian, denied its existence completely. The latter provided evidence and debated that inversion 
in language is not correct simply because it doesn't conform to rules of the standard language and hence, it is not more than an error deserving correction.

\subsubsection{Basra Versus Kuffa Schools Viewpoints}

Linguists following the famous linguistic school of Basra never confessed site or place inversion

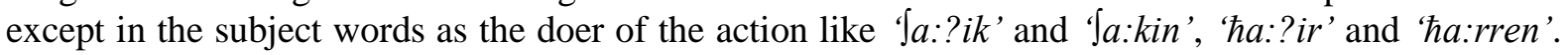
According to Almuzhir, one of the titles talking about the Basran linguists, true inversion is found in

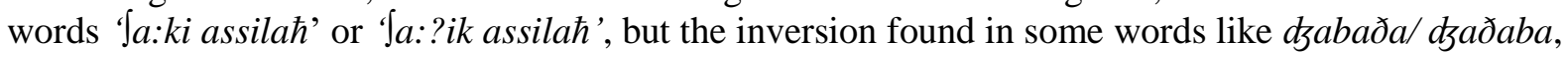
verb words, as the Kuffa linguists claimed is not inversion but two forms of the language.

The Basra school linguists consider the above cited examples besides many others to be spoken dialects not inversion and metathesis. The only explanation for this perspective is that when the inverted word is used by too many people and widely used through repetition, it becomes so familiar and natural among people as though it was an original word itself and then it is used for new derivations. This ability of inverted words to derive new words led them to think of them as stem words because of a rule they followed which says: if two words had the same stem they are equally original, if not, then, the one whose derivations are more numerous is the origin for the second.

However, the Kuffa school assumed correctly that metathesis in Arabic as in other languages, is a fact and those ancient Arab linguists (Basran traditional grammarians) who denied its existence neglected numerous examples showing its prevalence and wide use. As a matter of fact, metathesis is a phonological phenomenon of all languages with no exception. In both the everyday colloquial and the standard forms of Arabic language, many examples refute Ibn Darstawayh belief. These examples also refute the Basran school practice of restricting metathesis to some grammatical usage related to the subject doer. Lexical items such as: dzabaða/dzaðaba, dalmasa/damlasa, ikfahharra/ikrahhaffa,

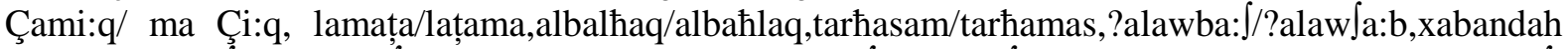

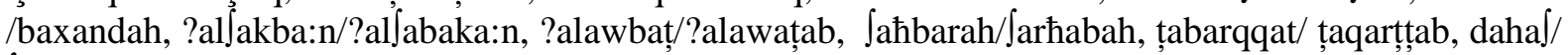
Jaddah, kursuf/ kurfus are justfew of many other examples of metathesis.

The researchers however, agree with the Kuffan perspective that the phonological inversion is the main factor for the abundance of these paired lexicals mentioned above and few others such as gadru:fl gardu:f, mizra:b/ mirza:b, tasa:ma/ tama:sa. In most of these inverted items, there is no definite rule that can generalize all cases; the cause is clear to be similar sounds in successive sequence or mishearing. However, sometimes some inverted sounds are rule-governed. There is a historical and syntactic regular formula : "?iftaÇala", inversion occurring according to this historical and standard formula is initiated due to a certain phonological sequence, inversions that don't conform to this formula were also working simply because of this instance.

\subsubsection{The Phonological Formula "?ftaÇala" in Arabic}

To clarify this standard formula "?iftaÇala", scholars of Semitic languages universally agree that it was originally "?itfaÇala", and the reason why it was itself reversed is due to the adjoining of the ' $t$ ' sound to the sibilant sound as noted in '?itsanada' and '?istanda'. The consequence of an explosive sound and a sibilant one is considered heavy not in Arabic alone, but in most languages. For ease and better pronunciation, site inversion immediately occurred between the $t$ and the sibilant sounds and thus the formula is converted from "?itfaÇala" into "?iftaÇala" to have '?istanada' for "?itsanada', and '?iltadda' for '?it $a d d a$ '. Later, this sort of inversion was generalized with all sounds to make them run alike. (Bergstrasser:1982) has said, the ' $t$ ' in (?iftaÇala) in Arabic comes always second to the $f$ sound in verbs while originally it comes first like in the Aramaic language such as 'etkri' and 'estima'.

The occurrence of site inversion happens when the explosive and fricative sounds are adjacent, and it is not restricted to Arabic but a general acoustic rule applied in languages in general. (Henry Flesh: 146,1966) has asserted this when he claimed that this phenomenon is not restricted to Arabic but a universal principle which states that a strong plosive sound plusa light sound tend to invert their sites.

In Hebrew the same principle is applied as noted in the successive of plosive and sibilant fricatives in words like 'hitsammer' which has been inverted to 'histammer'. In Soriano, we have 'etsmek' inverted to 'estmek', in Greek 'ttshwy' inverted to 'tsthwy'.

The inversion discussed above in the formula "?itfaÇala" affirms the fact that site inversion occurs mainly because of the difficulty of successive sounds sequence. Some examples in Standard Arabic: 
'damlasa' becomes 'dalmasa' in colloquial Arabic, and 'milÇaqa' becomes 'mi Çlaqa'. The ' $d$ ' and ' $m$ ' sound which are close according to their articulation and their sequence resulted in site inversion and thus the ' $l$ ' sound replaced the ' $m$ ' sound in damlasa/ dalmasa; the same applies to milÇaqa/ mi Çlaqa where the ' $l$ ' and ' $m$ ' replaced their positions to reduce the production of so closely uttered similar sounds.

\subsection{Metathesis in other Semitic languages}

In Semitic languages, metathesis is also phonologically governed. we find the word 'dipsu' in Akkadian came from the original word 'dispu'. Inversion in words of Hebrew takes place in lightsounds as in 'simla' which became 'salma' by inversion. The Semitic word 'tara' became 'tar' $a$ ' in Syriac; in Hebrew, it is 'saar'. The word 'efsentu' in Amharic became 'esfentu' by site inversion; here the site inversion took place between bilabial and sibilant sounds. It also takes place between the velar and sibilant as in 'nasaka' and its inverted word 'mankas'.

The word 'rukbah' in Arabic is an example of site inversion. The origin form of this word is 'burkah'. This is inferred from 'burku' in the Akkadian language, and 'berek' in Hebrew, 'burka' in Aramic, 'berk' in Amharic. Thus, in all Semitic languages the b sound precedes the ' $r$ ' and ' $k$ ' sounds; this is a clear evidence that 'rukba' in Arabic is the inverted form from 'burkah'. The word 'sullam' in Arabic is the same as 'sull.m' in Hebrew; whereas, it is 'sImmIltu' in Akkadian. The resemblance in both Arabic and Hebrew assures the inversion in Akkadian.

In non-Semitic languages, we find the proper name Alexander is the inverted form in Arabic for the name Aleskander. Bravmann (P,100,1977) said:",in Arabic, site inversion takes place between sibilant sounds and the " $w$ ' sound as in the word quwoos- qusoow."

Whatever true on standard words of Arabic or 'al-Fus-ha' is also applicable to the less formal forms

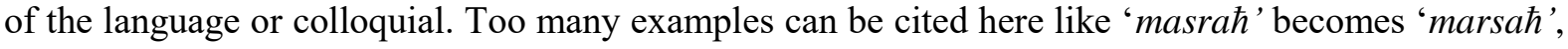
and 'dzawaz' becomes 'zawadb'.

\section{CONCLUSION}

Change in language seems to be a universal intrinsic behavior of, without this constant process it would have been labeled dead. Considered as minor sound change, metathesis, in this research is explored. The definition and causes of this important phenomenon are discussed here show how linguists approach it through phonological, morphological and syntactic approaches though each approach leading to different results. The western approach to metathesis is more appropriate since metathesis is the output of sound change. Spoonerism is related to metathesis as a special kind of this phenomenon due to another factor, i.e. slip of tongue. Under what conditions metathesis applies, why it happens, and how it interacts with other processes affecting sound structure are some of the questions this research has attempted to clarify. Whether phonological, morphological or syntactic, some of the linguistic changes remain vague and cannot be explained with certainty. After all, it seems that despite the fact that numerous cases of metathesis are reported in language, our basic knowledge lacks the full range of metathesis that is possible in language.

\section{REFERENCES}

[1] Baugh, Albert C.A History of the English Language. $5^{\text {th }}$ ed; Prentice Hall, 2002.

[2] Bloomfield, Leonard. Language. $12^{\text {th }}$ impression 1973, George Allen and Unwin. Ltd. London.

[3] Bolinger, Dwight. Aspects of language. Yale University Press, 1975.

[4] Bravmann, M.M. Studies in Semitic Philology. Leiden, 1977.

[5] HJEmslev, Louis. Language: An Introduction. Trans. Francis Whitfield. University of Wisconsin Press, 1975.

[6] Leopold, F.W. Werner. Child Language. Ed. Arvon Bar-Adov. Prentice Hall, New Jersey, 1971.

[7] Lord, Robert. Comparative Linguistics. The English University Pres Ltd, 1974.

[8] Musser, H. Paul. Manual of Child Psychology. $3^{\text {rd }}$ ed. USA, 1970.

[9] Sturtevant, E.H. An Introduction to Linguistics Science. Yale University, I964.

[10] Stevenson, Burton. Language: The Home Book of Quetotations. $3^{\text {rd }}$ ed. New York, 1975.

[11] Vendryes, J. Some Thoughts on Sound Laws. A Reader in Historical and Comparative Linguistics. Allan, R. Keiler. University of Michigan, Holt, Rinehart and Winston, Inc. 1972

[12] Wardhaugh, Ronald. Introduction to Linguistics. Megraw-Hill Book Company, 1972. 


\section{ARABIC REFERENCES}

المر اجع العربية:

الأقطش, عبد الحميد إتباع الإيقاع في اللغةألعربية مجلة أبحاث اليرموك م 12, ع2, سنة 1994. [1]

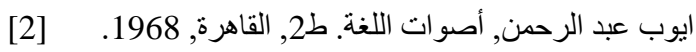

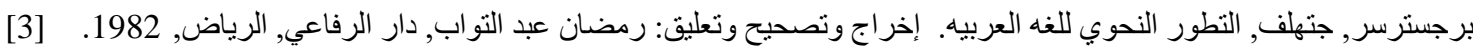

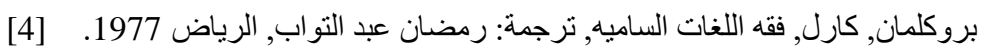

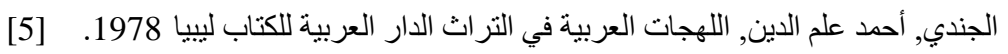

ابنجني ابو الفتح عثمانألخصائصتحقيقحمد عليالنجار القاهرة.

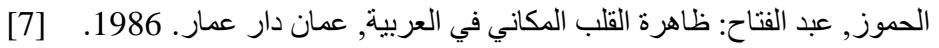

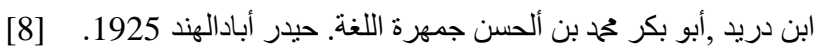

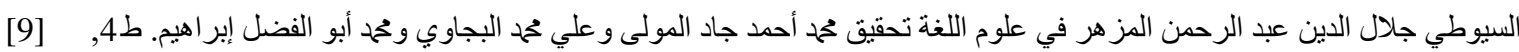
القاهرة 1958.

الثايب, فوزي حسن أثر القو انين الصوتيه في بناء الكلمه العربية, عالم الكتب الحديث, إربدـ الأردن, 2004 [10]

الصيغ, عبد العزيز: المصطلح الصوتي في الدراسات العربيه, بيروت, دار الفكر, 1998.

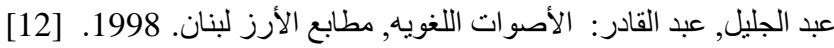

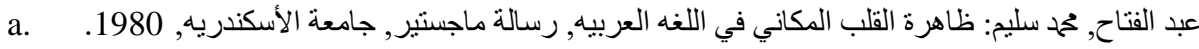

عبده, داوود, در اسات في علم أصوات اللغه العربيه, جامعة الكويت, 1984 1984.

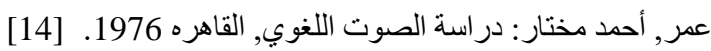

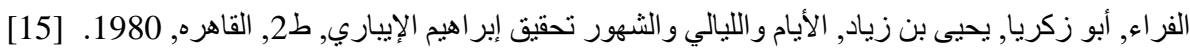

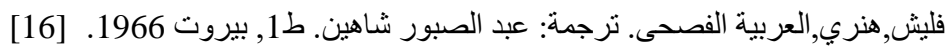

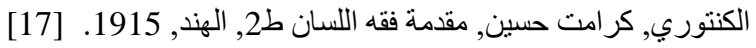

Citation: Raid Mohammad Saleh Khassawneh, Islam Mousa Al-Momani, Nibal Abdelkarim Malkawi. "Metathesis in Arabic: A Comparative Study" International Journal on Studies in English Language and Literature (IJSELL), vol 6, no. 5, 2018, pp. 19-25. doi:http://dx.doi.org/10.20431/2347-3134.0605003.

Copyright: (C) 2018 Authors. This is an open-access article distributed under the terms of the Creative Commons Attribution License, which permits unrestricted use, distribution, and reproduction in any medium, provided the original author and source are credited. 